\title{
CULTURE, APPARTENANCE ET DIALOGUE : TROUVER LA JUSTE ARTICULATION
}

\author{
Marc-Antoine Vallée* \\ marc-antoine.vallee@cegepmontpetit.ca
}

RÉSUMÉ Le principal objectif de ce texte est d'apporter certaines clarifications par rapport à des problèmes et difficultés entourant l'usage actuel des notions de culture, d'appartenance et de dialogue. L'auteur montre que l'idée selon laquelle on pourrait être prisonnier de sa propre culture découle d'une transformation récente de la signification du concept de culture. Cette idée est critiquée comme étant un mythe, le mythe de la monade culturelle, reposant sur une mécompréhension des rapports entre culture, appartenance et dialogue. L'auteur s'efforce de proposer une meilleure compréhension de ces trois concepts, de façon à éviter toute forme de relativisme radical.

Mots clés Culture, Dialogue, Vérité, Relativisme, Herméneutique, Ontologie.

ABSTRACT The aim of this paper is to shed light on some difficulties and problems related to the current use of the concepts of culture, belonging and dialogue. The author shows that the idea that we could be prisoners of our own culture stems from a recent transformation of the meaning of the concept of culture. This idea is criticized as a myth, the myth of the cultural monad, based on a misunderstanding of the relationship among culture, belonging and dialogue. The author tries to offer a better understanding of these three concepts, in order to avoid any form of radical relativism.

Keywords Culture, Dialogue, Truth, Relativism, Hermeneutics, Ontology. 


\section{Introduction}

La visée principale de cet article est d'aborder un certains nombres de difficultés et problèmes liés à notre compréhension, ou mécompréhension, actuelles des notions de culture, d'appartenance et de dialogue, ainsi que de leurs articulations. Je tâcherai, d'abord, de mettre en lumière quelques transformations récentes et moins récentes de la notion de culture, qui a rendu possible l'idée selon laquelle nous pourrions en quelque sorte être enfermés dans notre propre culture particulière ou prisonniers de certains schèmes culturels. Cette idée connaît sa formulation la plus radicale dans ce que je décrirai comme le "mythe de la monade culturelle", dont je m'efforcerai d'expliciter et de critiquer la logique qui lui est sous-jacente. Je soutiendrai alors que ce mythe, qui se trouve formulé ou présupposé chez différents penseurs du $20^{\mathrm{e}}$ siècle et du $21^{\mathrm{e}}$ siècle, offre une vision inadéquate des rapports entre culture, appartenance et dialogue, débouchant sur un relativisme généralisé. Je montrerai ensuite que le mythe de la monade culturelle n'est qu'un exemple des difficultés que nous éprouvons à bien définir la nature de l'articulation complexe entre les notions de culture, d'appartenance et de dialogue. Nous verrons que devant ces difficultés, nous sombrons trop souvent dans différents excès qu'une juste articulation nous permettrait d'éviter. C'est cette articulation adéquate que je chercherai, enfin, à définir.

\section{Du sens de la culture}

La notion de culture est aujourd'hui particulièrement présente dans les nombreuses discussions politiques et sociales autour du multiculturalisme ou de l'interculturalisme, soit dans les débats sur les différentes politiques et pratiques sociales entourant l'organisation du pluralisme ou de la diversité culturelle. À travers le modèle multiculturel ou le modèle interculturel, on cherche à répondre aux défis que pose la coexistence d'une pluralité de "cultures" au sein d'un même corps politique soucieux de respecter des principes démocratiques d'égalité, de liberté et de respect des minorités. On s'interroge notamment sur les risques de ghettoïsation des différentes communautés culturelles ou de fragmentation du tissu social. Pour ma part, ce qui me frappe le plus dans ces discussions et débats autour du multiculturalisme ou de l'interculturalisme, c'est quelque chose de plus sous-jacent, qu'on présuppose sans questionner, à savoir la façon dont la notion de culture se voit le plus souvent comprise comme une source de particularisation plutôt qu'un renvoi à l'universel. Il semble désormais aller de soi que la culture soit moins ce qui rassemble les gens par-delà leurs particularismes que ce qui permet à un 
individu ou à un groupe de se distinguer des autres par ses particularismes. Le fait premier n'est pas une pluralité de personnes se retrouvant dans l'espace de la culture commune, mais une pluralité de communautés ou d'individus se différenciant par la culture qui leur est propre. Si on remonte au $17^{\mathrm{e}}$ ou au $18^{\mathrm{e}}$ siècle, un tel usage de la notion de culture n'aurait pas manqué de susciter perplexités et circonspections. Cet usage particularisant de la notion de culture ne semble s'intégrer progressivement à l'usage courant qu'avec la montée en puissance du nationalisme européen et l'idée de "culture nationale". Chaque nation aurait une identité propre en raison de sa culture nationale particulière, qui se distingue des autres cultures nationales, notamment par une certaine confession religieuse (catholique, protestante, anglicane, etc.), prenant parfois la forme d'une Église d'État, et par l'usage d'une langue particulière dont les grands auteurs sont les principaux représentants. Ainsi, la culture anglaise brille de tous ses feux dans la langue de Shakespeare; la culture française trouverait une expression parfaite dans la langue de Molière, etc. Ayant sa propre langue, sa propre religion, ses propres œuvres culturelles, coutumes et traditions, qui s'enracinent dans une histoire particulière et dans un territoire particulier, chaque nation aurait développé au fil du temps une vision du monde qui lui serait propre. Chaque culture posséderait un génie particulier qui se manifesterait dans les chefs d'œuvres de ses artistes et dans les traités de ses penseurs les plus importants.

Il est important de se rappeler que toutes ces idées, dont on retrouve les premières traces au $18^{\mathrm{e}}$ siècle, ne deviennent largement répandues qu'au cours $19^{\mathrm{e}}$ siècle. Avant cela, par exemple, les grands traités scientifiques et philosophiques étaient rédigés en latin (puis parfois traduits dans les différentes langues nationales), si bien que les penseurs et les savants européens communiquaient d'abord entre eux dans une langue supranationale, et que la culture dépassait nécessairement les frontières des États-nation. Dans cette perspective humaniste, antérieure au nationalisme européen de la fin du $18^{\mathrm{e}}$ siècle puis du $19^{\mathrm{e}}$ siècle, la notion de culture renvoyait d'abord et avant tout à l'idée de cultiver l'esprit humain, de former sa pensée, pour s'élever à la raison universelle. S'éduquer ou se cultiver impliquait donc nécessairement le fait de dépasser ses particularismes pour s'ouvrir à des horizons plus vastes qui sont ceux de la culture universelle. Cette intelligence de la culture résonne encore chez certains penseurs du $19^{\mathrm{e}}$ siècle, en commençant par Hegel pour qui la formation culturelle (Bildung) est synonyme d'élévation à l'universalité, comme le rappelle Gadamer dans "Vérité et méthode" (1996, pp. 25-31).

Mais cette fragmentation du champ de la culture en une pluralité de cultures nationales hétérogènes les unes par rapport aux autres, pour laquelle 
il y a autant de cultures que de nations, n'aura été visiblement qu'une première étape dans une fragmentation beaucoup plus vaste du champ culturel. C'est qu'à partir du moment où la culture peut être ce qui distingue un ensemble de personnes par rapport à un autre ensemble de personnes, autrement dit quand la culture devient source de particularisation plutôt que ce qui nous fait aller au-delà de nos particularismes, la logique se déploie de façon presque incontrôlable ets'applique constamment à de nouveaux cas. Quand la distinction se limitait à celle entre des cultures nationales, la culture se présentait à la fois comme ce qui rassemble ou ce qui est commun à une pluralité d'individus particuliers, mais aussi ce qui distingue ce groupe relativement homogène et particulier d'un autre groupe relativement homogène et particulier. Mais on pouvait déjà théoriquement procéder à des distinctions au sein même d'une nation particulière entre des formes de cultures plus régionales, par exemple différencier la culture napolitaine de la culture vénitienne. Ces distinctions ne venaient toutefois pas trop ébranler la relative homogénéité de la culture nationale qui restait le point de référence. Les choses se complexifient nettement au $20^{\mathrm{e}}$ siècle, à travers les nombreuses vagues d'immigrations et le processus de mondialisation, qui force les États-nations à composer avec un pluralisme des populations inédit. Cela entraîne le fait que plusieurs cultures particulières (majoritaires ou minoritaires) coexistent désormais dans un même pays, dans des rapports parfois harmonieux, parfois conflictuels. Dans ce contexte, la distinction à partir de l'identité culturelle se complique en raison de la multiplication des ramifications. On peut désormais être à la fois de culture chinoise et américaine, ou encore de culture indienne et anglaise. Par ailleurs, l'identification culturelle ne se limite plus à l'identification à une ou plusieurs cultures nationales. La culture se décline selon les différentes appartenances d'un individu : appartenance nationale (brésilien), religieuse (protestant), à une classe sociale (bourgeois), à une langue (portugais), à un mouvement politique (progressiste), etc. Devant cette multiplication des particularismes possibles, on en vient parfois à dire que chacun a sa propre culture, ce qui voudrait dire que chacun combinerait de façon originale une multitude d'appartenances lui donnant une perspective unique sur le monde. Cette intelligence nouvelle de la notion de culture se voit consacrée à travers les cultural studies dans le monde anglo-saxon, où le multiculturalisme est le plus avancé.

Dans une conférence intitulée "La crise de notre temps" (1962), Leo Strauss évoque cette transformation en profondeur du concept de culture au cours des $19^{\mathrm{e}}$ et $20^{\mathrm{e}}$ siècles, non sans un certain sarcasme : 


\begin{abstract}
Que veut donc dire aujourd'hui le mot culture? En anthropologie et dans certaines parties de la sociologie, le mot "culture" est toujours, bien entendu, employé au pluriel, et de telle manière que vous avez une culture des banlieues, une culture des bandes de jeunes, non délinquants et même délinquants. Et vous pouvez dire, selon cette notion récente de culture, qu'il n'y a pas un seul être humain qui ne soit cultivé puisque chacun appartient à une culture. En même temps, heureusement, la notion ancienne de culture se maintient encore; [...] lorsque nous parlons d'un être humain cultivé nous sous-entendons encore que tous les êtres humains ne sont pas cultivés ou ne possèdent pas la culture. Si nous projetons notre regard à la fin du chemin, on peut dire que, selon l'opinion qui prévaut aujourd'hui dans les sciences sociales, chaque être humain qui n'est pas interné dans un asile de fous est un être humain cultivé. Et aux confins de la recherche, dont on nous parle tellement aujourd'hui, nous trouvons la question intéressante de savoir si les pensionnaires d'un asile de fous n'ont pas eux aussi une culture propre (Strauss, 2004, pp. 102-103).
\end{abstract}

Si on laisse de côté le dédain manifeste de Leo Strauss pour ce nouvel usage de la notion de culture, sa remarque a l'intérêt de montrer clairement qu'entre l'usage élitiste qu'on pouvait faire de cette notion et l'usage radicalement égalitaire qu'on fait très souvent aujourd'hui, il y a deux façons bien différentes de comprendre ce qu'est la culture. Une notion de culture qui s'utilise normalement au singulier, désignant l'éducation de l'esprit humain en vue de la raison universelle (conception humaniste), et une notion de culture qui s'utilise au pluriel et qui renvoie plutôt aux conditions ou situations particulières de chacun (conception sociologique).

\title{
Le mythe de la monade culturelle
}

Le recul de l'intelligence humaniste de la culture comme élévation à l'universel au profit de la culture comme source de particularisation accompagne l'essor et le développement de la pensée historiciste en réaction à la philosophie de l'histoire de Hegel. De même que chaque nation possède sa propre culture, il semble que chaque époque posséderait un esprit particulier dont les œuvres artistiques et philosophiques seraient l'expression. Ainsi chaque culture, chaque société et chaque époque seraient porteuses d'une certaine vision du monde, que l'on pourrait découvrir à travers les productions artistiques et philosophiques qui en témoignent. Cette conception présuppose que la pensée de tout individu soit influencée, voire déterminée, par l'époque, la société ou la culture auxquelles elle appartient. Il ne fait aucun doute que cette prise de conscience du rôle déterminant de nos appartenances culturelles dans la formation de notre esprit est importante puisqu'elle est un rappel de la finitude de toute pensée individuelle et des conditions qui la rendent possible. Mais à la lumière de nombreux prolongements et développements 
de cette idée dans les sciences humaines et sociales et dans la philosophie "postmoderne", il est désormais manifeste que le danger est de sombrer dans une interprétation relativiste et fataliste de nos appartenances culturelles pour laquelle nous serions tout simplement prisonniers d'un certain nombre de "schèmes culturels", rendant par le fait même contestable toute prétention à la vérité ou à une compréhension adéquate de ce qui est. Pour reprendre ce qu'évoquait Leo Strauss, le "mythe de la monade culturelle" suggère que nous sommes peut-être tous des fous dans un asile, ligotés par notre culture propre comme dans une camisole de force.

La logique sous-jacente au "mythe de la monade culturelle" se présente de la façon suivante : toute culture repose sur un langage constitué de concepts qui véhiculent une certaine ontologie ou un découpage du réel. Entre nous et la réalité, il y aurait donc un intermédiaire qui viendrait organiser le contenu de nos expériences à partir de schèmes conceptuels de façon à offrir un portrait particulier de notre monde. Par suite, les langues et les cultures très différentes véhiculeraient des visions du monde concurrentes et incommensurables, dont on ignore cependant la validité de chacune. Pour évaluer, la justesse d'une vision du monde donnée par rapport aux autres visions du monde, il faudrait être capable de s'extirper de nos schèmes conceptuels, et donc de se détacher parfaitement de notre culture et de notre langage, pour comparer les différents schèmes à la réalité elle-même. Or nous ne disposons malheureusement pas d'un tel accès direct à une réalité neutre, puisque toute pensée s'appuie inévitablement sur un certain langage et se forme à partir d'horizons culturels particuliers. En l'absence d'un tel point d'Archimède, nous serions à jamais enfermés dans des schèmes culturels médiatisant le rapport de notre esprit à la réalité. Dans ce contexte, c'est l'idée même d'une réalité indépendante de nos schèmes culturels et de nos interprétations qui devrait ultimement être abandonnée puisqu'elle ne possèderait pas plus de réalité que la chose en soi chez Kant. En l'absence d'une telle réalité neutre, il n'y a plus aucun sens à prétendre que nos descriptions ou nos interprétations du monde sont plus justes ou plus adéquates que celles de n'importe qui d'autre. Nous nous retrouvons donc devant un relativisme généralisé, dont des penseurs comme Gianni Vattimo et Richard Rorty n'hésitent pas à prendre la défense et à faire la promotion.

Ce mythe de la monade culturelle et le relativisme généralisé dont il est porteur s'accompagnent souvent d'un culte de l'altérité qui leur serait complémentaire. En effet, si chacun est d'une façon ou d'une autre prisonnier de ses schèmes culturels, il est pour le moins discourtois, pour ne pas dire barbare, de venir contredire les prétentions à la vérité d'une autre personne, 
qui ne partage pas les mêmes schèmes ou catégories de pensée que nous. Dans ce contexte, c'est l'ambition même de comprendre autrui qui devient le signe d'une violence grossière, puisque cela ne serait rien d'autre que la tentative d'enfermer l'Autre dans mes propres schèmes conceptuels ou culturels. Chercher à comprendre l'Autre, alors que son altérité résiste nécessairement à tous mes efforts de compréhension, serait faire violence à cet Autre dans son altérité radicale. Bref, l'Autre ne doit pas être compris, il doit simplement être respecté dans son altérité irréductible. Pour Gianni Vattimo, cette violence à l'endroit de l'autre homme dans sa différence est intimement liée à la volonté métaphysique de comprendre la réalité véritable en elle-même, en commençant par celle de l'homme. Elle découle surtout de la prétention illégitime de la métaphysique à pouvoir y arriver. Selon Vattimo (2007, pp. 400-421), en effet, c'est la métaphysique elle-même (qui a forgé les principaux schèmes culturels de la pensée occidentale), qui est intrinsèquement violente de par son ambition démesurée de saisir la réalité essentielle des choses et les premiers principes dont tout dépend. Par suite, l'élucidation de ces rapports complexes entre violence et métaphysique serait l'un des problèmes centraux de la philosophie contemporaine, comme l'attestent les œuvres de Heidegger, Adorno, Levinas, Derrida et Girard. Seule une critique radicale de la métaphysique serait en mesure de nous libérer de cette violence de la métaphysique enfin remplacée par une éthique de la "pensée faible" reposant sur un nihilisme herméneutique.

Il y a, selon moi, des raisons sérieuses de résister à cette dénonciation unilatérale de la métaphysique occidentale et surtout à ce mythe de la monade culturelle pour lequel chacun serait en quelque sorte prisonnier de ses schèmes culturels, incapable de connaître le monde lui-même et de comprendre l'autre dans sa différence. D'abord, il ne fait aucun doute qu'une telle position débouche sur un relativisme fort qui se heurte, comme toute pensée de ce type, à de nombreuses contradictions logiques. La position que défendent ces penseurs est-elle plus vraie que celle de tous ceux qui les contredisent? Si oui, c'est donc qu'ils ont une meilleure connaissance que les autres de la réalité et de ce qui doit être respecté. Et si ce n'est pas le cas, à quoi bon les écouter? Ensuite, l'idée selon laquelle nous serions irrémédiablement prisonniers de nos schèmes culturels semble tous les jours invalidée par l'expérience qui est la nôtre à différents niveaux. Par exemple, l'apprentissage des langues étrangères et le travail de la traduction montrent bien que nous ne sommes pas irrémédiablement enfermés dans les schèmes linguistiques de notre langue maternelle, mais qu'il est toujours possible de comprendre l'autre dans sa propre langue, tout comme il m'est ensuite possible de rendre compte de sa pensée dans ma propre langue. Cela est bien sûr l'évidence même, mais il 
importe de le rappeler puisqu'une telle réalité tient presque du miracle si on se place du point de vue de la monade culturelle, qui peut difficilement expliquer une telle chose, puisque nos conceptions du monde seraient incommensurables. Contre cette idée, des herméneutiques comme celles de Gadamer et Ricœur ont fortement défendu la thèse d'une traductibilité de principe entre toutes les langues (voir Vallée, 2012, pp. 133-144). L'apprentissage des langues étrangères et le travail de traduction rendent possible un dialogue entre des personnes venant d'horizons culturels complètement différents. C'est d'ailleurs ce qui rend possible le travail de l'anthropologue ou de l'ethnologue, qui cherchent à comprendre l'organisation et la culture de sociétés humaines qui nous sont profondément étrangères. C'est également ce qui permet à l'historien ou au philologue de comprendre les cultures et les textes d'autrefois, même si nous ne partageons pas nécessairement les "catégories" ou "schèmes culturels" des hommes et des femmes qui vivaient à cette époque.

L'expérience nous montre donc tous les jours que les cultures vivantes ne sont pas des monades, sans porte ni fenêtre, mais des horizons susceptibles de s'étendre pour accueillir ce qui nous est d'abord parfaitement étranger. Ce ne sont pas des réalités figées ou momifiées, mais bien des réalités dynamiques, qui vivent des échanges et rencontres avec des façons distinctes ou concurrentes de penser et d'agir. Par opposition, si on accepte le mythe de la monade culturelle, c'est tout le rapport à autrui qui devient problématique, voire incompréhensible. Est-ce à dire que la réflexion intense de la philosophie contemporaine et des sciences humaines et sociales sur l'impact de nos appartenances culturelles sur notre façon d'interpréter et de comprendre le monde devrait tout simplement être oubliée? Absolument pas! Cette réflexion est un moment important dans la prise de conscience que nos appartenances à une culture donnée peuvent entraîner une mécompréhension de ce qui est étranger à notre horizon culturel, qui est toujours un horizon limité. Elle se montre donc particulièrement utile quand elle fait ressortir certains préjugés ou présupposés liés à notre époque, notre société ou à notre culture, qui nous empêchent de comprendre les pensées, les œuvres ou les actions de personnes vivant dans d'autres horizons historiques ou culturels. Mais dans la mesure où cette prise de conscience de nos préjugés ou présupposés problématiques nous permet (non sans efforts) d'aller au-delà de ceux-ci en libérant de nouvelles possibilités de compréhension, on retrouve d'une certaine manière la conception humaniste selon laquelle la culture est ce qui permet de dépasser certains de nos particularismes pour accéder à des réalités plus vastes que le petit monde qui nous est d'abord familier. 


\section{La tension entre culture, appartenance et dialogue}

Plutôt que de parler d'enfermement dans des schèmes culturels, de violence de nos efforts de compréhension et de respect de l'altérité radicale d'autrui, il m'apparaît indiqué de chercher une articulation plus adéquate entre culture, appartenance et dialogue. Concernant la notion de culture, je crois qu'il faut retenir quelque chose des trois étapes de son développement comme culture universelle, culture nationale et culture particulière. L'idée selon laquelle chacun posséderait ou s'inscrirait dans une culture particulière a le mérite de nous rappeler que toute personne pense et interprète le monde à partir d'une situation culturelle particulière où se déploient des horizons qui lui sont propres. Mais les différentes appartenances culturelles que peut cumuler un individu, dans une combinaison singulière, sont aussi des appartenances partagées avec d'autres, puisqu'une culture purement individuelle serait aussi problématique et contradictoire qu'un langage privé. Ma culture autochtone est ce qui me rattache aux autres autochtones de ma communauté, ma culture italienne est ce qui me relie à l'ensemble des Italiens, mon éducation musulmane est ce qui m'unit à l'ensemble des musulmans dans le monde, etc. Bref, nos différentes appartenances culturelles ne contribuent pas simplement à définir notre singularité, mais nous rattachent toujours aussi à des groupes ou communautés sur une échelle locale, nationale ou internationale. L'un des grands défis que pose le pluralisme grandissant des sociétés occidentales est certainement celui que doivent affronter les différents corps politiques dans l'effort pour rassembler des populations de plus en plus hétérogènes. On se demande en effet comment éviter à la fois le repli identitaire vers des formes violentes de nationalisme, sans pour autant réduire le lien social au simple partage d'une même citoyenneté? Comment préserver une culture commune offrant un espace de partage favorisant le vivre-ensemble d'une société donnée? C'est à ce défi que les penseurs actuels du multiculturalisme et de l'interculturalisme cherchent activement à répondre à leur façon. Mais ce défi ne sera relevé que si un dialogue interculturel est capable de s'ouvrir entre les membres de la société d'accueil et les nouveaux arrivants, et si chacun accepte de dépasser certains de ses particularismes afin de mieux comprendre l'autre et trouver un mode respectueux de vivre-ensemble. Cela signifie retenir la leçon de l'humanisme pour lequel la culture est un vaste espace d'échange ou de dialogue auquel on n'accède que si chacun s'efforce d'élargir ses horizons particuliers pour accéder à un savoir plus vaste et viser l'universel.

De ce point de vue, on peut affirmer que les notions de culture, d'appartenance et de dialogue sont animées par une certaine tension qui leur confère une dynamique. Tout ce que nous avons dit sur les différentes 
acceptions de la notion de culture nous permet de voir que la culture vit d'une tension entre le particulier et l'universel. Ainsi, il convient de penser nos appartenances culturelles dans une double perspective. Nos appartenances constituent une inscription nécessaire dans des horizons culturels formateurs pour notre pensée, qui nous donne un point de vue sur le monde, mais qui nous place inévitablement dans une perspective située et limitée. Nos appartenances culturelles doivent ainsi être comprises comme des conditions de possibilité pour la pensée et la compréhension de ce qui est, mais également comme une perspective particulière qui ne domine jamais toutes choses. D'où l'importance du dialogue comme ouverture à la perspective d'autrui, qui peut bousculer mes appréhensions, présuppositions ou catégories, qui peut me faire voir ou connaître les choses de façon inédite. Le dialogue vit précisément de la tension entre l'irrémédiable finitude de chacun des interlocuteurs et la nécessaire ouverture à la parole de l'autre.

\section{Deux formes d'excès}

Ces tensions qui habitent les rapports entre culture, appartenance et dialogue entraînent la possibilité d'excès opposés visant à abolir ou occulter l'un ou l'autre des principes. Une première forme d'excès consiste dans différentes formes d'enfermement dans les particularismes, de repli identitaire sur les appartenances, ou de fixation sur une tradition morte ou figée. Dans ce type d'excès, on oublie complètement la dimension universelle de la culture. Ce qui est étranger se présente systématiquement comme une menace pour notre culture, notre identité nationale ou nos traditions. Cela a été bien analysé sur le plan politique par Martha Nussbaum, dans son récent livre sur "Les religions face à l'intolérance" (2012), qui s'intéresse aux politiques actuelles de peur face aux minorités religieuses (surtout musulmanes) en Occident. Elle montre bien comment cela peut se présenter de façon différente selon les contextes politiques. Pour résumer très schématiquement son propos, les importantes difficultés d'intégration que rencontrent aujourd'hui la plupart des pays européens découleraient principalement d'une conception plutôt restrictive de l'appartenance à la nation héritée du passé. Comme l'écrit Nussbaum :

En Europe, où est né l'État-nation moderne, la notion d'appartenance nationale s'enracine dans des caractéristiques difficiles, sinon impossibles, à partager pour de nouveaux immigrants. Pour ces nations, fortement influencées par le romantisme, l'appartenance à un même sang, à un même sol, à un même ensemble 
ethnolinguistique et une même religion sont des éléments nécessaires, ou du moins essentiels, à l'identité nationale" (Nussbaum, 2012, p. 33).

Cette conception de l'appartenance nationale impose bien évidemment des critères si contraignants que la plupart des immigrants ne pourront jamais remplir, pas même en partie. Selon Nussbaum, cela expliquerait donc pourquoi "les migrants fraîchement arrivés et les minorités religieuses sont rarement perçus comme des membres égaux à part entière de la nation" (2012, p. 137). Si cette conception de l'appartenance nationale a été fortement ébranlée par les horreurs de la Seconde Guerre mondiale, elle reste malgré tout présente dans certaines couches de la population et constitue une inspiration importante pour certains mouvements nationalistes plus conservateurs qui s'alimentent aujourd' hui de la peur que suscite la présence grandissante de l'islam en Europe. Ces politiques de peur prendraient une forme différente dans le monde anglosaxon et principalement aux États-Unis, où règne une définition plus inclusive de l'appartenance nationale pensée davantage en termes d'adhésion à des buts et idéaux politiques communs. Bien qu'il n'ait pas la même langue maternelle ou la même religion que la majorité, l'immigrant pourrait ainsi plus facilement être reconnu comme un membre à part entière de la nation pour autant qu'il adhère aux principes de liberté, d'égalité et de respect qui structurent le vivreensemble. Cette intelligence plus inclusive de l'appartenance nationale ne rend cependant pas la population américaine imperméable à toute crainte par rapport à certaines minorités, comme en témoignent son histoire, de même que le climat de peur qui s'est installé depuis le traumatisme suscité par les attentats du 11 septembre 2001. Tout l'ouvrage de Nussbaum vise précisément à nous mettre en garde contre les politiques de stigmatisation des populations musulmanes et les dérives islamophobes. Quand règne l'émotion narcissique de la peur, qui ne voit plus dans l'étranger qu'une possible menace à notre vie ou à notre patrie, il n'y plus d'espace de dialogue et de compréhension mutuelle possible. Ce n'est plus que le moment de la méfiance qui inspire le repli ou la persécution.

À ce premier type d'excès répond un excès contraire qui se manifeste dans un effacement complet de soi à travers l'ouverture à l'autre, dans l'évasion dans une universalité purement formelle et sans contenu, ou encore dans une valorisation abusive du dialogue pour le dialogue. Ce type d'excès est souvent moins frappant puisqu'il semble essentiellement motivé par une ouverture généreuse à l'autre, mais il n'est pas moins néfaste quand sa logique est poussée à bout. Dans un tel excès, nous assistons à une relativisation complète de nos principes bien ancrés et de nos convictions profondes, ou encore se voit nourrie et entretenue une haine de soi illégitime qui espère 
couper notre pensée et nos pratiques de toutes formes d'enracinement culturel et historique. S'ouvrir à l'autre ne veut pas dire s'effacer totalement devant lui, mais accepter au contraire d'être pour lui un véritable interlocuteur, prêt à débattre avec lui et non pas à acquiescer bêtement à tout ce qu'il pourra dire. Si pour rencontrer l'autre, il est souvent nécessaire de réviser certaines de nos idées préconçues et de nous défaire de nos préjugés, cela ne veut jamais dire rejeter en bloc sa propre culture et ses propres traditions de peur d'imposer automatiquement je ne sais quelle vision colonialiste ou ethnocentriste. Comme l'indique le précepte populaire, il ne faut pas jeter le bébé avec l'eau du bain. Contre cette dérive, les herméneutiques de Gadamer et Ricœur ont à juste titre insisté sur le fait que toute pensée se déploie sur le fond d'un certain nombre d'appartenances culturelles et historiques, qui rendent possibles la pensée elle-même. Si on peut dire que c'est un espoir illégitime et vain que celui de mettre à distance l'ensemble des appartenances qui nous forment, puisque toute pensée, qu'elle le veuille ou non, s'inscrit inévitablement dans des horizons linguistiques, historiques et culturels déterminés, en retour tout l'effort de la pensée à travers l'éducation, l'apprentissage des langues et des cultures étrangères, ainsi que l'effort pour comprendre sa propre culture, vise à étendre les horizons de notre pensée et à prendre conscience du sol dans lequel elle s'enracine. En ce sens, toute dynamique culturelle s'appuie sur une tradition vivante qui s'expose au regard critique, qui s'ouvre à la possibilité de révisions, et qui cherche constamment à repenser et reformuler ce qu'elle véhicule dans un langage plus parlant ou plus vivant pour nous aujourd'hui.

À travers la confrontation à des œuvres d'art et à la littérature universelle, avec l'étude des sciences humaines et sociales et grâce au dialogue interculturel, la pensée peut prendre conscience, dans une certaine mesure, du point de vue nécessairement limité qui est le sien sur la complexité des phénomènes humains. Mais cette prise de conscience de la finitude de notre pensée ne devrait jamais se résoudre dans un fatalisme paresseux. Elle doit servir au contraire de signal pour l'éveil de notre curiosité et de motivation pour chercher à comprendre l'autre à partir de son point de vue et des raisons qui le motivent. C'est là le sens de la culture, d'un point de vue humaniste, que de refuser l'enfermement dans nos particularismes pour s'exposer à d'autres perspectives. Dans le contexte du pluralisme des sociétés occidentales, les bienfaits du dialogue sont également très souvent vantés. Cela est certainement louable. Comme on le dit souvent, personne n'est contre la vertu! Toutefois, si on ne veut pas se limiter à dire des banalités, il faut savoir ce qu'on entend ici par “dialogue". Si ce n'est qu'un espace de discussion où chacun a l'occasion d'exprimer ses opinions personnelles, en assumant le principe relativiste selon 
lequel toutes les opinions se valent, on aura beaucoup de mal à établir en quoi un tel "dialogue" diffère d'une simple succession de monologues et ce qu'on peut en espérer. Gadamer (1996, pp. 385-402) a bien montré qu'il y a, au contraire, une exigence propre au dialogue qui implique la visée d'une entente sur la chose même, une authentique recherche de la vérité, à travers la confrontation des convictions et arguments de chacun. Même si cette entente peut échouer, et appeler à une reprise ou un approfondissement ultérieurs de la discussion, l'important est qu'un véritable dialogue implique une telle visée de la chose même ou de la vérité, et donc qu'il soit réellement animé par une quête d'universalité. Le dialogue exige de chacun qu'il fournisse ses meilleurs arguments pour convaincre les autres du bien fondé de ses prétentions à la vérité, qu'il accepte que ses arguments subissent l'épreuve de la confrontation avec les prétentions des autres et qu'il fasse un effort soutenu pour comprendre l'autre dans la perspective qui est la sienne. En somme, un véritable dialogue est quelque chose de difficile et exigeant, qui n'a rien à voir avec le simple bavardage qui occupe aujourd'hui tant de place dans les médias et dans les réseaux sociaux.

\section{Conclusion}

Par-delà les deux formes d'excès qui ont été identifiées, il convient donc d'établir comme principe général la nécessité de rechercher un juste équilibre, une articulation adéquate, entre les notions de culture, d'appartenance et de dialogue. C'est une telle recherche qui anime les œuvres de Gadamer et Ricœur, quand elles tentent de dépasser des oppositions figées ou trop tranchées au profit d'articulations plus subtiles entre raison et tradition, vérité et histoire, critique et conviction, ouverture et appartenance, dialogue et autorité, universel et particulier. Et c'est d'une telle approche herméneutique dont on devrait s'inspirer pour affronter les défis actuels du multiculturalisme ou de l'interculturalisme. La juste articulation entre culture, appartenance et dialogue me semble impliquer une tension dynamique entre les trois notions sans qu'une des trois notions ne vienne éclipser les autres. Là où on valoriserait la culture seule aux dépens de nos appartenances et du dialogue, nous risquerions de nous trouver dans un universalisme abstrait qui méconnaît la complexité du réel et les efforts de la pensée pour atteindre l'universel. Par ailleurs, là où ne règneraient que les appartenances, nous serions confrontés aux risques d'un repli abusif sur nos particularismes, d'une répétition mécanique de traditions sans vie, ou d'un enfermement dans nos "schèmes culturels". Enfin, là où ne règnerait que le dialogue pour lui-même, nous n'aurions plus de point de 
vue d'où parler, ni de visée du vrai ou de l'universel pour nous aiguillonner. Toute culture ouvre, pour qui y participe, un certain nombre d'horizons et vit du dialogue qui l'anime. Toute appartenance à une culture est formatrice pour la pensée et donne une certaine compréhension du monde à partir de laquelle nous pouvons entrer en dialogue et chercher la vérité. Tout dialogue authentique implique un échange entre des prétentions concurrentes à la vérité et un effort pour saisir la perspective de l'interlocuteur. Ainsi, l'important est de chercher le bon équilibre, l'articulation adéquate entre culture, appartenance et dialogue, sans espérer arriver trop aisément à des accords définitifs entre les interlocuteurs, sans non plus se montrer impatient en rompant le dialogue et se repliant sur ses particularismes, mais en contribuant vaillamment à la recherche commune de la vérité et d'une meilleure compréhension mutuelle qui est la vocation première de la culture.

\section{Bibliographie}

DERRIDA, J. "L'écriture et la différence". Paris : Seuil, 1967.

GADAMER, H.-G. (1960). "Vérité et méthode". Traduction de P. Fruchon, J. Grondin et G. Merlio. Paris : Seuil, L'ordre philosophique, 1996.

NUSSBAUM, M. C. "Les religions face à l'intolérance. Vaincre la politique de la peur". Traduction de Nathalie Ferron. Paris : Climats, 2012.

RICCEUR, P. "Temps et récit”, tome 3. Paris : Seuil, 1985.

RORTY, R. "Philosophy and the Mirror of Nature". Princeton : Princeton University Press, 1980.

STRAUSS, L. "Nihilisme et politique". Traduction d'Olivier Sedeyn. Paris : Rivages poche, Petite bibliothèque, 2004.

VALLÉE, M.-A. "Gadamer et Ricœur. La conception herméneutique du langage". Rennes : Presses universitaires de Rennes, 2012.

VATTIMO, G. "Metaphysics and Violence". In : S. Zabala (ed.), 2007. pp. 400-421. ZABALA, S. (ed.). "Weakening Philosophy. Essays in Honour of Gianni Vattimo". Montréal/Kingston : McGill-Queen's University Press, 2007. 